\title{
STRUCTURAL EVOLUTION OF SPUTTERED INDIUM OXIDE THIN FILMS
}

\author{
Ivan Hotový $^{*}$ - Thomas Kups ${ }^{* *}$ - Juraj Hotový ${ }^{*}$ - Jozef Liday ${ }^{*}$ \\ — Dalibor Búc ${ }^{*}$ _ Mária Čaplovičová ${ }^{* * *}$ — Vlastimil Řeháček ${ }^{*}$ \\ - Helmut Sitter ${ }^{* * *} \_$Clemens Simbrunner \\ Alberta Bonnani ${ }^{* * *}$ L Lothar Spiess ${ }^{* *}$
}

\begin{abstract}
The indium oxide thin films were deposited at room temperature by reactive magnetron sputtering in the mixture of oxygen and argon on silicon and oxidized silicon substrates. The influence of the oxygen flow in the reactive mixture and post-deposition annealing on the structural properties were investigated. The as deposited $\operatorname{In}_{2} \mathrm{O}_{3}$ films showed a dominating randomly oriented nanocrystalline structure of cubic $\mathrm{In}_{2} \mathrm{O}_{3}$. The grain size decreased with increasing oxygen concentration in the plasma. Annealing in reducing atmospheres (vacuum, nitrogen and argon), besides improving the crystallinity, led to a partial cubic to rhombohedral phase transition in the indium oxide films.
\end{abstract}

K e y w or d s: $\mathrm{In}_{2} \mathrm{O}_{3}$ thin films, dc magnetron sputtering, structure, cubic indium oxide, rhombohedral indium oxide

\section{INTRODUCTION}

Indium oxide belong among transparent conducting oxides are widely used in various applications thanks to their low resistivity, high optical transparency and wide band gap. These applications include using in solar applications, the transparent electrodes in various optoelectronic devices, the barrier layers in tunnel junctions, the active layers of gas sensors or the material for ultraviolet lasers [1]. Therefore, there have been a lot of works on investigations of their growth conditions and studying their properties in dependence on the synthesis methods ranging from such as evaporation, sputtering, sol-gel process and chemical pyrolysis to metal organic chemical vapour deposition [2-4].

$\mathrm{In}_{2} \mathrm{O}_{3}$ thin films have a good adherence to the substrate surface and high chemical inertness [5]. In general, undoped binary oxide films are insulators in their stoichiometric form. On the other hand, this property can be changed by suitable doping and controlling the concentration of oxygen vacancies. $\mathrm{In}_{2} \mathrm{O}_{3}$ can appear in two stable modifications as body-centered (bcc) cubic ( $a=10.118 \AA)$ and rhombohedral (rh) $(a=5.478 \AA$ and $c=14.51 \AA$ ) (crystallographic data are taken from [6]). They can be stabilized by choosing appropriate deposition conditions or synthesis methods $[7,8]$. The rhombohedral phase has been rarely produced and it exhibits better physical properties than the cubic one. The difference seems to be the results packing of the anion layers in the rhombohedral $\mathrm{In}_{2} \mathrm{O}_{3}[9]$.

In this study, XRD, HRTEM and SAED were used for study of the structural evolution of indium oxide films. It was found that annealing of cubic phase will cause, besides recrystallization of the film, partial phase transition from the cubic into the rhombohedral phase.

\section{EXPERIMENTAL DETAILS}

The $\mathrm{In}_{2} \mathrm{O}_{3}$ films were deposited by dc reactive magnetron sputtering from an In target $\left(4^{\prime \prime}\right.$ in diameter, $99.99 \%$ pure) in a mixture of oxygen and argon onto unheated Si and oxidized Si substrates. A sputtering power of $75 \mathrm{~W}$ was used. Both argon inert flow and oxygen reactive flow were controlled by mass flow controllers. The flow of oxygen in the reactive mixture $\mathrm{O}_{2}$-Ar was changed in the range of $40-80 \mathrm{sccm}$. The relative partial pressure of oxygen, defined as $p\left(\mathrm{O}_{2}\right) / p\left(\mathrm{O}_{2}+\mathrm{Ar}\right)$, varied from 10 to $30 \%$. The total gas pressure was kept constant at $0.8 \mathrm{~Pa}$ and adjusted by a piezoceramic valve. Some of the deposited films were post-growth annealed in a tube furnace for 1 hour at 400 and $500{ }^{\circ} \mathrm{C}$ in $\mathrm{N}_{2}$ and Ar atmospheres as well as in vacuum.

The crystal structure was identified with a ThetaTheta X-ray diffractometer (XRD) D 5000 with a Goebel mirror in grazing incidence geometry with $\mathrm{CuK} \alpha$ radiation. Further structural features of the films were investigated by means of a Tecnai 20 S-TWIN transmission electron microscope (TEM) operated at $200 \mathrm{kV}$. It is equipped with energy dispersive X-ray (EDX) facility for high resolution chemical analysis. Selected electron diffraction (SAED) patterns have been recorded together with bright and dark field images of the film structure.

\footnotetext{
Department of Microelectronics, Slovak University of Technology, Ilkovičova 3, 81219 Bratislava, Slovakia, ivan.hotovy@stuba.sk; ** FG Werkstoffe der Elektrotechnik, Institut für Werkstofftechnik, TU Ilmeau, Postfach 100565, 98684 Ilmenau, Germany; ${ }^{* * *}$

Department of Geology of Mineral Deposits, Comenius University, Mlynská dolina, 84215 Bratislava; ${ }^{* * * *}$ Institute of Semiconductor and Solid State Physics, Johannes Kepler University, Altenbergerstr. 69, A-4040 Linz, Austria
} 


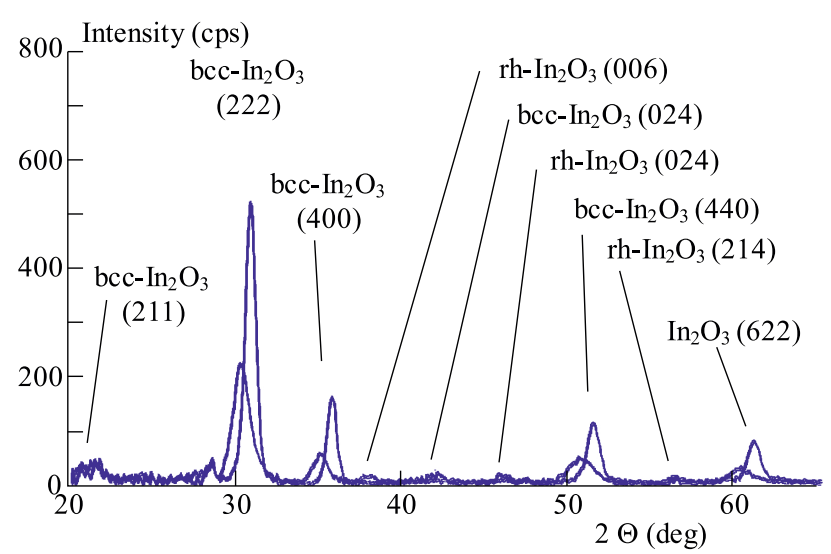

Fig. 1. XRD diffraction patterns of $\mathrm{In}_{2} \mathrm{O}_{3}$ films: as-deposited at a relative oxygen partial pressure of $20 \%$ and annealed at $500{ }^{\circ} \mathrm{C}$ in nitrogen, (black line represents as-deposited sample, grey line represents annealed samples)

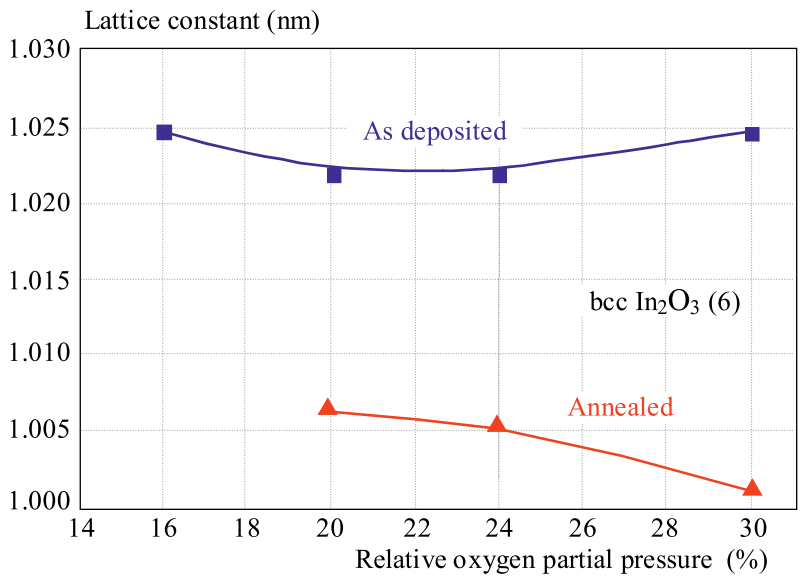

Fig. 2. Lattice constants of the (bcc) indium oxide fraction in the film in dependence on the relative oxygen partial pressure in the working gas for as deposited and annealed at $500{ }^{\circ} \mathrm{C}$ samples. The horizontal line indicates the lattice constant of unstrained bcc $\mathrm{In}_{2} \mathrm{O}_{3}$

\section{RESULTS AND DISCUSSION}

The typical XRD diffractograms taken from the indium oxide layer after deposition and annealed at $500{ }^{\circ} \mathrm{C}$ for $1 \mathrm{~h}$ in nitrogen are shown in Fig. 1 . The XRD patterns revealed a clear polycrystalline structure. The diffraction patterns consist of diffraction peaks related to the (bcc) structure of $\mathrm{In}_{2} \mathrm{O}_{3}$ and corresponding to (211), (222), (400), (440) and (622) lattice planes correlating with the results obtained in [5]. The strongest diffraction peak is the peak related to the (222) lattice plane indicating corresponding preferential orientation along this direction. After annealing all diffraction peaks were shifted towards higher $2 \Theta$ angles by $0.5^{\circ}-0.9^{\circ}$, as depicted in Fig. 1 . This implies that the process of post-deposition annealing at $500{ }^{\circ} \mathrm{C}$ has shrunk the lattice constant or caused a change in the residual strain between the lattice planes, resulting in a decrease of the lattice parameter. The obtained lattice plane values extracted from the diffraction peaks before and after annealing are given in Fig. 2. In the as deposited case the lattice constants are increased as compared with the unstrained value of the lattice parameter for (bcc) $\mathrm{In}_{2} \mathrm{O}_{3}$ which is $1.0118 \mathrm{~nm}$ [6]. The experimentally obtained lattice parameters are in the range between 1.021 and $1.026 \mathrm{~nm}$ for as-deposited samples. After annealing the lattice parameter drops below the theoretical value and is within the range of 1.001 and $1.006 \mathrm{~nm}$. Such drastic changes are a common effect in sputtered oxide films [5] and can be attributed to out-diffusion of the implanted sputter gases, defect annealing and defectdefect interaction.

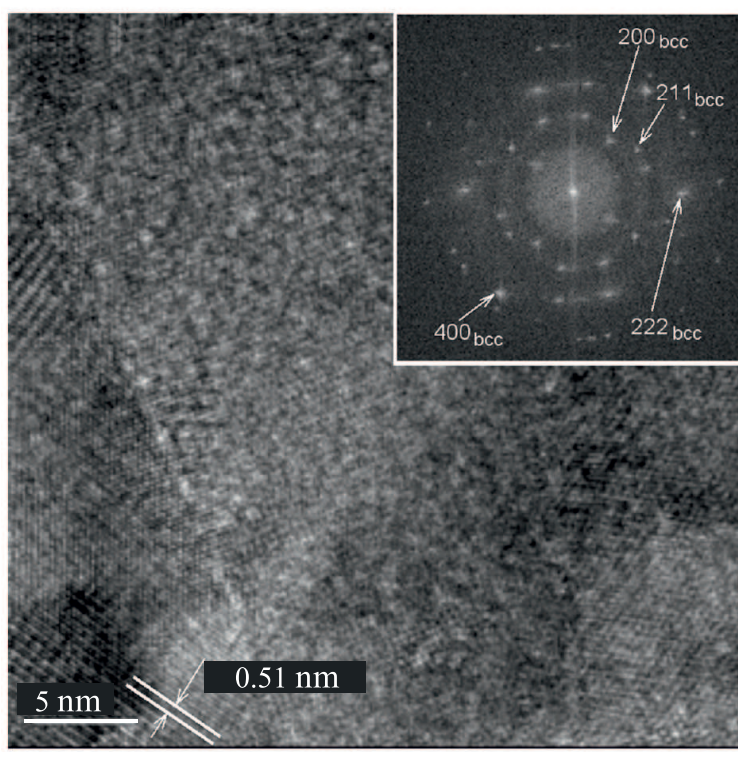

Fig. 3. HRTEM image of $\mathrm{In}_{2} \mathrm{O}_{3}$ as-deposited film at a relative oxygen partial pressure of $15 \%$. The inset shows the FFT image of the thin film

Further reasons for the change in the lattice constants can be oxygen vacancy formation and differences in the thermal expansion coefficients between the substrate and the thin film. The intensities of the diffraction peaks were also significantly higher (at least two times in comparison with as-deposited) for all annealed samples. Moreover, the values of the full-width at half-maximum (FWHM) of the annealed samples were smaller, indicating better crystallinity of the indium oxide film due to the carried out annealing procedure. Additionally, if the relative oxygen partial pressure was equal to or exceeds $15 \%$ another remarkable change was observed. Namely, the appearance of weak additional diffraction peaks in the diffraction pattern of the annealed sample. The peak positions correspond to the (006), (024) and (214) lattice planes of the rhombohedral modification of indium oxide. Therefore, in consequence of the thermal annealing, the initial cubic structure was partially transformed into a rhombohedral structure. The rhombohedral polymorphic modification of indium oxide is the so-called high pressure phase [9], $i e$, this phase is metastable at normal pressures.

The nanostructural characterization of several $\mathrm{In}_{2} \mathrm{O}_{3}$ thin films has been carried out via TEM, HRTEM and 

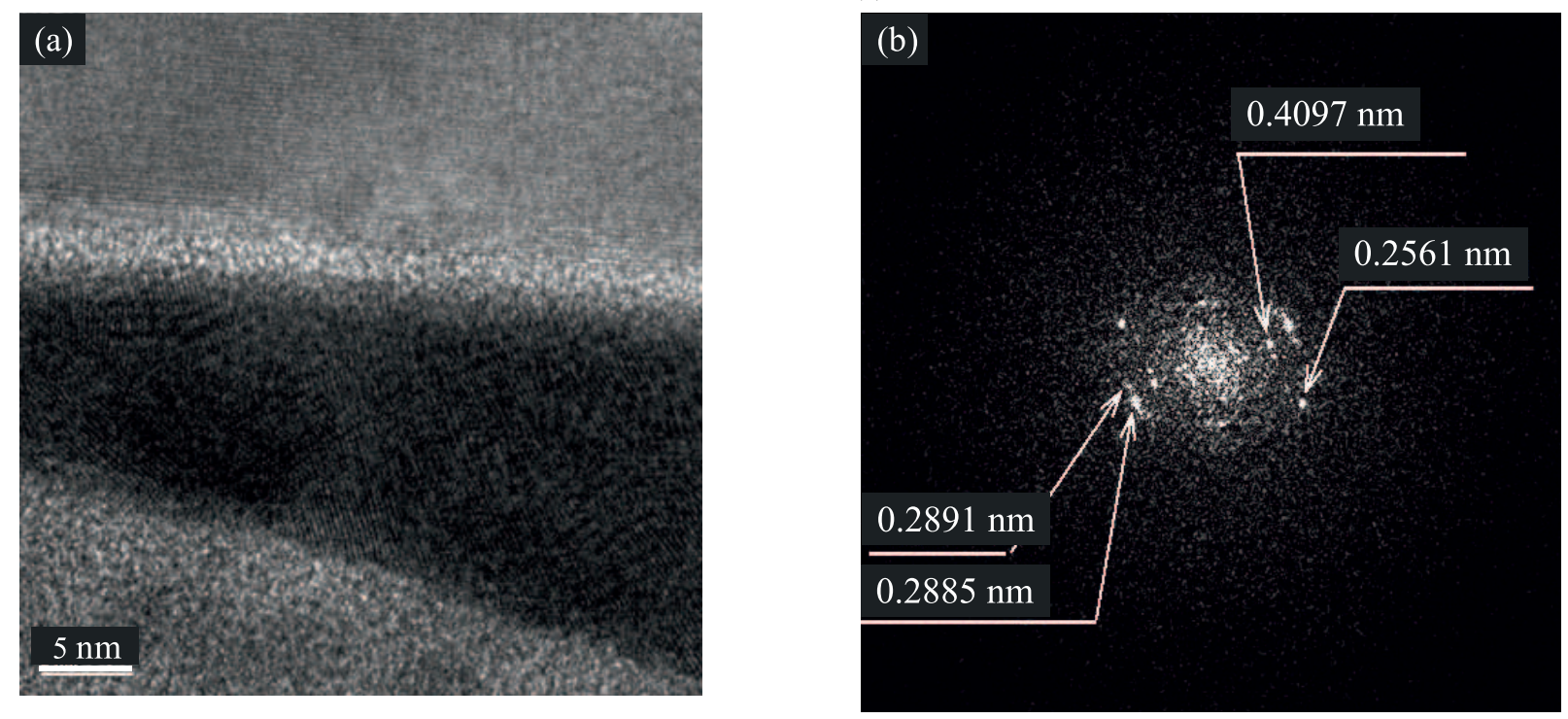

Fig. 4. HRTEM image (a)- and FFT pattern (b)- of $\mathrm{In}_{2} \mathrm{O}_{3}$ film prepared at a relative oxygen partial pressure of $20 \%$ and annealed at $400^{\circ} \mathrm{C}$ in vacuum

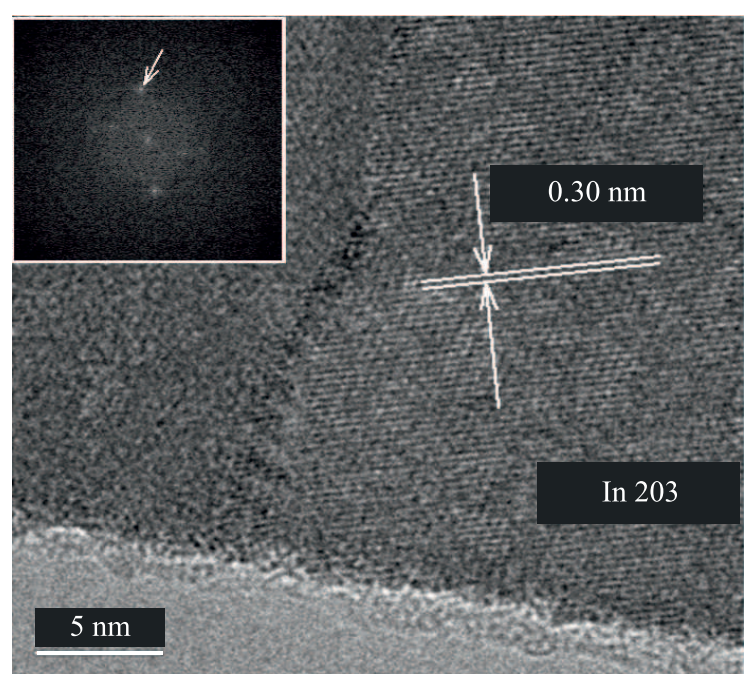

Fig. 5. HRTEM image of $\operatorname{In}_{2} \mathrm{O}_{3}$ film prepared at a relative oxygen partial pressure of $20 \%$ and annealed at $400{ }^{\circ} \mathrm{C}$ in Ar atmosphere

SAED. HRTEM observations (Fig. 3) of as-deposited $\mathrm{In}_{2} \mathrm{O}_{3}$ films confirmed that they were polycrystalline with fine-grained, however, they differ in gain size and thickness of the film. The size of the nanocrystals forming the layer ranges was about $20 \mathrm{~nm}$ for samples prepared at $15 \%$ oxygen content in sputtering gas while the size of crystallites decreased into the range under the $10 \mathrm{~nm}$ in the film deposited at $30 \%$ oxygen content (not shown herein). Confirmation of the presence of $\operatorname{In}_{2} \mathrm{O}_{3}$ in the deposited film has been obtained from SAED analyses. The FFT patterns of both as-deposited films cosisted of spots creating the rings indicating a polycrystalline nature of film with high crystallinity of individual grains. By evaluation of FFT patterns (inset in Fig. 3) it was confirmed the presence of (bcc) structure of $\mathrm{In}_{2} \mathrm{O}_{3}$.
The effect of post-deposition annealing was investigated for $\mathrm{In}_{2} \mathrm{O}_{3}$ films deposited at a relative oxygen partial pressure of $20 \%$. In generally, during the annealing a coalescence of $\operatorname{In}_{2} \mathrm{O}_{3}$ nanocrystals has been observed. It was observed that in the case of annealing at $400{ }^{\circ} \mathrm{C}$ in vacuum (Fig. 4) the film maintained $\mathrm{In}_{2} \mathrm{O}_{3}$ (bcc) structure, however, measured interlayer distances $0.2885 \mathrm{~nm}$ and $0.2891 \mathrm{~nm}$ may be assigned both cubic and also rhombohedral $\operatorname{In}_{2} \mathrm{O}_{3}$ phases (222 diffraction of cubic $\operatorname{In}_{2} \mathrm{O}_{3}$ has $0.2921 \mathrm{~nm}$, ICCD 6-0416, and 104 diffraction of rhombohedral $\mathrm{In}_{2} \mathrm{O}_{3}$ is $0.2883 \mathrm{~nm}$, ICCD 21-0406).

In the case of annealing at $400^{\circ} \mathrm{C}$ in $\mathrm{Ar}$ atmosphere uniform $\mathrm{In}_{2} \mathrm{O}_{3}$ film was observed. From measured interlayer distance of $0.3 \mathrm{~nm}$ obtained from HRTEM image (Fig. 5), it was not possible to distinguish between cubic and rhombohedral phases in this TEM cross section. We assume that although the majority of reflexes in FFT patterns obtained from various places of prepared film unequivocally confirm the presence of (bcc) $\mathrm{In}_{2} \mathrm{O}_{3}$ phase in the layer, the reflexes with the measured interlayer distances $0.3002 \mathrm{~nm}, 0.268$, and $0.2986 \mathrm{~nm}$ can be assigned also to rhombohedral $\mathrm{In}_{2} \mathrm{O}_{3}$ phase that was confirmed using XRD measurements for samples after annealing. Therefore, additional detailed TEM and XRD observations will be necessary for confirmation the transition from the (bcc) polymorphic modification into the rhombohedral modification of indium oxide due to annealing.

\section{CONCLUSIONS}

Structural evolution of indium oxide thin films deposited at room temperature by reactive magnetron sputtering and annealing in a reducing atmosphere were investigated. Indium oxide films were polycrystalline with the size of nanocrystals ranging from a few nanometres 
to $10 \mathrm{~nm}$. Annealing in the reducing atmospheres shrinks the layer thickness and improves the crystallinity due to recrystallization and out-diffusion of incorporated gases as a consequence the residual strain in the layer, which causes a partial phase transition from the (bcc) polymorphic modification into the rhombohedral modification of indium oxide.

\section{Acknowledgements}

This work has been supported by the Scientific Grant Agency of the Ministry of Education of the Slovak Republic and the Slovak Academy of Sciences, No 1/0553/09, $1 / 0779 / 10,1 / 0337 / 08$, by the Slovak Research and Development Agency under the contract No VVCE-0049-07, PPP programme of DAAD No. D/08/07742 and Action R/S No. 63s7.

\section{REFERENCES}

[1] XU, J.-CHEN, Y.: J. Shen: Mater. Lett. (2008), 1363.

[2] MALAR, P.-MOHANTY, B. CH.-BALAMURUGAN, A. K.-RAJAGOPALAN, S.-TYAGI, A. K.-KASIVISWANATHAN, S. : Surf Interface Anal 37 (2005), 281.

[3] BEENA, D.-LETHY, K. J.-VINODKUMAR, R.-MAHADEVAN, V. P.-GANESAN, V.-PHASE, D. M.-SUDHEER, S. K. : Applied Surface Science 255 (2009), 8334.

[4] KOROTCENKOV, G.-BRIDZARI, V.-IVANOV, M.-CERNEAVSCHI, A.-RODRIGUEZ, J.-CIRERA, A.-CORNET, A.-MORANTE, J. : Thin Solid Films 479 (2005), 38.

[5] PRATHAP, P.-GOWRIDEVI, G.-SUBBAIAH, Y. P. V.RAMAKRISHNA REDDY, K. T.-GANESAN, V.: Curr. Appl. Phys. 8 (2008), 120.

[6] ICDD PDF-2 Data base, JCPDS-Int. Center for Diffraction Data, Pensylvania, 1994.

[7] WANG, C. Y.-CIMALLA, V.-ROMANUS, H.-KUPS, T.ECKE, G.-STAUDEN, T.-ALI, M-LEBEDEV, V.-PEZOLDT, J.-AMBACHER, O.: Appl. Phys. Lett. 89 (2006), 011904.

[8] WANG, C. Y.-DAI, Y.-PEZOLDT, J.-LU, B.-KUPS, T.-CIMALLA, V.-AMBACHER, O.: Cryst. Growth \& Design 8 (2008), 1257.

[9] ATOU, T.-KUSABA, K.-FUKUOKA, K.-KIKUCHI, M.SYONO, Y.: J. Solid State Chem. 89 (1990), 378.

Received 2 March 2010

Ivan Hotový received his MSc in Electronics from the Slovak University of Technology in Bratislava in 1982 and his $\mathrm{PhD}$ in Electronics from the Slovak University of Technology in 1994. He is a scientific worker and lecturer at Department of Microelectronics, FEIT STU. His current research interests include the development of gas sensors, magnetron sputtering of metal oxide films and plasma etching of compound semiconductors.

Juraj Hotový received his MSc in Microelectronics from the Slovak University of Technology in Bratislava in 2009. He is a PhD student in Department of Microelectronics, FEIT STU. His current research interests include the characterization of electrical, optical and structural properties of transparent conductive oxides for solar cells application.
Jozef Liday (Assoc Prof, PhD) graduated in solid state physics in 1968 and received his $\mathrm{PhD}$ in electronics and vacuum technology, both from STU, in 1985. His teaching and research activities include materials analysis, thin films and surface science.

Dalibor Búc graduated in solid state physics and received his $\mathrm{CSc}(\mathrm{PhD})$ in electronics and vacuum technology, both from the Slovak Technical University, in 1971 and 1980, respectively. Since 1981 he has worked as a scientist in the field of thin film technology and plasma processing (reactive magnetron sputtering, ion plating, ion beam sputtering) at the Department of Microelectronics FEI STU.

Vlastimil Řeháček received his MSc in Nuclear Chemistry from the Comenius University in Bratislava in 1982 and his PhD in Electronics from the Slovak University of Technology in 2005. He is a scientific worker in Department of Microelectronics, FEIT STU. His current research interests include the development of voltammetric sensors, gas sensors and photolithography.

Thomas Kups received his Diploma in 2001 in the Department of Physics and his PhD in 2006 in the Department of Physics and Astronomy from the FriedrichSchiller-University Jena, Germany. Since 2006, he is a scientific researcher at the Technical University Ilmenau. His recent research focuses on the transmission electron microscopy investigations of III-Nitrides, metal-oxides and $\mathrm{SiC}$.

Lothar Spiess is a Proffessor at Department of Materials Technology, Technical University of Ilmenau. His interest is concern to material microanalysis and semiconductor processing.

Mária Čaplovičová (Ing, CSc), was born in 1957 in Lozorno, Slovakia. She worked in the field of physical metallurgy and experimental methods of material analysis. The main part of research work was associated with the study of continuity of microstructure and properties of ferromagnetic materials and of nanomaterials using high resolution electron microscopy, electron diffraction and $\mathrm{x}$ ray microanalysis.

Helmut Sitter (Assoc Prof, PhD) graduated in 1975 and received his $\mathrm{PhD}$ in technical physics in 1980, both from the University of Linz. His research and teaching activities include the technology and diagnostics of advanced semiconductor structures and devices.

Clemens Simbrunner graduated in solid state physics from the JKU Linz. His scientific interests include growth of the gallium nitride structures by MO CVD technology and diagnostic of semiconductor structures. Currently he is a member of the Group of Epitaxy at Institute of Semiconductor and Solid State Physics, JKU Linz.

Alberta Bonnani ( $\mathrm{PhD}$ ) graduated in solid state physics from the University of Trieste, Italy, and received her $\mathrm{PhD}$ from the University of Linz in 1999. She has been with the University of Linz, the field of her interest is optical characterization of epilayers. 